\title{
Factors Affecting the Participants' Skills Test Performance in a Basic Life Support Course
}

\author{
Saerah Iffat Zafar1 and Alina Shahiryar² \\ ${ }^{1}$ Department of Radiology, Armed Forces Institute of Radiology and Imaging (AFIRI), Rawalpindi, Pakistan \\ ${ }^{2}$ Department of Prosthodontics, Islamic International Dental College (IIDC), Islamabad, Pakistan
}

\begin{abstract}
Objective: To determine the effect of age, gender, varying specialties and year of residency on the practical skills of cardiopulmonary resuscitation in participants of basic life support (BLS) courses run at College of Physicians and Surgeons Pakistan (CPSP), Islamabad - Regional Centre of American Heart Association (AHA).

Study Design: Cross-sectional study.

Place and Duration of Study: College of Physicians and Surgeons of Pakistan (CPSP), Islamabad - Regional Centre of American Heart Association (AHA), from February 2013 to November 2016.

Methodology: A total of 269 candidates participating in BLS courses were included in the study. Their age, gender, specialty, year of training and status (trainee or supervisor) were recorded. Results of practical skills were collected and data were compiled using Statistical Package for the Social Sciences (SPSS) version 17, to determine the factors affecting the outcome of BLS skills test.

Results: Junior residents performed better than the senior residents in their practical skills, while other factors including age, gender and specialty did not significantly alter the outcome of BLS skills performance.

Conclusion: Better performance of junior residents compared to their senior counterparts implies that BLS training should be introduced at the beginning of the resident programme when residents are fresh into their training followed by refresher courses. Age, gender or specialty does not affect the performance of doctors' practical skills of BLS.
\end{abstract}

Key Words: Basic life support (BLS), Cardiopulmonary resuscitation (CPR), Residents, Performance, Skill test.

How to cite this article: Zafar SI, Shahiryar A. Factors affecting the participants' skills test performance in a basic life support course. J Coll Physicians Surg Pak 2019; 29(9):810-3.

\section{INTRODUCTION}

Cardiopulmonary resuscitation plays a vital role in saving lives of people with cardiac arrest. Correct method, prompt reaction and immediate compressions and rescue breathing can make a difference between life and death. ${ }^{1}$ Hence, the importance of regular training of healthcare professionals so that precious lives can be saved. The participants undergoing BLS courses are taught the correct technique of chest compressions and rescue breaths, in addition to training regarding use of automated external defibrillator (AED) as part of skill training under the prescribed guidelines provided by American Heart Association (AHA). Use of AED reduces the deaths by half in cardiac arrest in out-of-hospital scenarios of critical patients. ${ }^{2}$ Since just the basic knowledge of cardiopulmonary resuscitation (CPR) and $A E D$ is required to reduce the mortality in patients of cardiac arrest, therefore it is imperative to teach these

Correspondence to: Dr. Saerah Iffat Zafar, Department of Radiology, Armed Forces Institute of Radiology and Imaging (AFIRI), Abid Majeed Road, Rawalpindi, Pakistan

E-mail: saerah_syk07@yahoo.com

Received: January 14, 2019; Revised: May 07, 2019;

Accepted: June 14, 2019 basics to young budding residents in all specialties as part of their residency programme. A study conducted at Shifa Hospital, Islamabad between January to December 2005 revealed that prompt cardiopulmonary resuscitation within the hospital was associated with better outcomes for patients with cardiac arrest. ${ }^{3}$

BLS programme has been included in the curriculum of the fellowship and membership residents' training by CPSP so that every resident, regardless of specialty, is required to attend and clear BLS training course before their intermediate module (IMM) as part of fellowship, or Membership programme (MCPS). Senior doctors are also required to undertake BLS course before being enrolled as supervisors in different specialties. There is also an increasing stress worldwide on providing basic and advanced life support courses at undergraduate as well as junior doctors' level so that they are well prepared to deal with life-saving situations, both mentally and physically. 4

The aim of this study is to identify the impact of various factors such as gender, age, specialty and year of training of doctors with their skills performance at the end of BLS course run by postgraduate College of Physicians and Surgeons Pakistan (CPSP) as a regional center of American Heart Association (AHA). 


\section{METHODOLOGY}

It was a cross-sectional study conducted at CPSP Islamabad - the Regional Centre for American Heart Association (AHA). A total of 269 participants attending the basic life support (BLS) provider courses being conducted by the author as AHA certified BLS Instructor between February 2013 to November 2016 were included in the study. Candidates who were not doctors were excluded from the study.

Age, gender, specialty and their status as trainees or supervisors and year of training (less than 2 years of training considered as junior residents; more than two years as senior), along with results of the BLS provider course for both adult and infant BLS skills were recorded for each candidate. BLS courses skills testing is based on proformas provided by AHA, which includes performance testing for skills of CPR/use of pocket masks and bag masks for breath provision, separately for adults and infants. In addition, candidates are also tested for use of AED for adults. Testing is conducted objectively on provided proformas, minimising the bias due to the exam being conducted by different instructors. Participants were rated as good performers, if they cleared the skills test in first attempt, or after remediation of adult or infant BLS. They were rated as poor performers, if they failed or cleared the test after remediation in both adult and infant BLS.

Data was fed into Statistical Package for Social Sciences (SPSS) version 17. Descriptive statistics and Chi-square / Fisher's exact test were conducted to determine the significance of association.

\section{RESULTS}

Out of 269 candidates, $51 \%$ were females $(n=137)$, while $49 \%$ were males $(n=132)$; maximum belonged to age less than 30 years $(51.7 \%, n=139) ; 34.6 \%(n=93)$ were between $30-39$ years of age while $13.8 \% \quad(n=37)$ were 40 years or above. Surgical and allied specialties included general and special surgery, gynaecology, ophthalmology, oto-orolaryngeology and anaesthesia; this group made up $40.1 \%$ of the total participants $(n=108)$, medical and allied including general and special medicine, family medicine, paediatrics, psychiatry and rehabilitation medicine was the next largest group of candidates at $39 \%(n=105)$. Participants in third group were diagnosticians (radiologists and pathologists) and those in basic sciences, making up $16.4 \%(n=44)$, while those belonging to dental surgery were $4.5 \%(n=12)$ of total candidates.

Skill test results were evaluated with respect to age, gender and specialty of the participants. Chi-square test was used to compare any difference in the frequency distribution of good and poor performance among participants with regard to age, gender, specialties and between junior/senior residents. Chi-squared test was
Table I: Frequency distribution of different factors affecting skills performance of participants along with their $p$-values in a BLS course.

\begin{tabular}{|c|c|c|c|c|}
\hline Factors & $\begin{array}{c}\text { Good } \\
\text { performance }\end{array}$ & $\begin{array}{c}\text { Poor } \\
\text { performance }\end{array}$ & Total & $p$-value \\
\hline \multicolumn{5}{|l|}{ a. Gender } \\
\hline Male & $92(67.2 \%)$ & $45(32.8 \%)$ & $137(100 \%)$ & 0.93 \\
\hline Female & $88(66.7 \%)$ & $44(33.3 \%)$ & $132(100 \%)$ & \\
\hline \multicolumn{5}{|l|}{ b. Age } \\
\hline$<30$ years & $95(69.3 \%)$ & $44(31.7 \%)$ & $139(100 \%)$ & 0.83 \\
\hline $30-39$ years & $60(64.5 \%)$ & $33(35.5 \%)$ & $93(100 \%)$ & \\
\hline$>39$ years & $25(67.6 \%)$ & $12(32.4 \%)$ & $37(100 \%)$ & \\
\hline \multicolumn{5}{|l|}{ c. Specialty } \\
\hline Surgical / allied & $80(74.1 \%)$ & $45(32.8 \%)$ & $108(100 \%)$ & 0.23 \\
\hline Medical / allied & $65(61.9 \%)$ & $40(38.1 \%)$ & $105(100 \%)$ & \\
\hline Diagnostics / basic sci & $27(61.4 \%)$ & $17(38.6 \%)$ & $44(100 \%)$ & \\
\hline Dental & $8(66.7 \%)$ & $4(33.3 \%)$ & $12(100 \%)$ & \\
\hline \multicolumn{5}{|l|}{ d. Year of residency } \\
\hline Junior residents & $90(71.4 \%)$ & $36(28.6 \%)$ & $126(100 \%)$ & 0.054 \\
\hline Senior residents & $73(59.8 \%)$ & $99(40.2 \%)$ & $122(100 \%)$ & \\
\hline
\end{tabular}

used to compare the performance levels among participants; no significant difference was found with regard to performance between gender $(p=0.93)$, age $(p=0.83)$ and among various specialties $(p=0.23)$; however, performance of junior residents in BLS skills test, in comparison to senior residents, was found to be borderline insignificant with $(p=0.054$, Table I).

\section{DISCUSSION}

Cardiac arrest is a major cause of mortality in both inpatients and out-of-hospital occurrence. According to a study, cardiac arrest has emerged as a leading cause of death in developing countries, exceeding those due to human immune deficiency virus (HIV), malaria and tuberculosis, disease mostly prevalent in such regions. ${ }^{5}$ Cardiopulmonary resuscitation makes a profound difference in patients with cardiac arrest; timing of CPR is crucial, as there is damage to vital organs within minutes leading to irreversible damage, hence proper technique and timely institution of CPR cannot be emphasised enough. CPR provides a window between the cardiac arrest and installation of life saving management, during which the chances of survival of a patient increase dramatically. 6 CPSP has collaborated with $A H A$, in order to impart training of BLS as part of its curriculum for its postgraduate programme. The aim is to train all the doctors regardless of their specialty and status (resident/supervisor) so that precious lives may be saved while being in hospital as well as out-ofhospital situations. This study has revealed borderline insignificant outcome in performance of junior and senior residents as compared to other groups. This could have been significant if the sample size was larger, this highlights the limitation of this study which is a small sample size. It is recommended that BLS courses should be run early in the residency programmes, with the need for refresher courses later in the years to keep 
abreast of the changes in knowledge and techniques as recommended by the American Heart Association (AHA). ${ }^{7}$ Age of the resident, their specialty and gender had no significant impact on the skills of BLS among the participants.

A study carried out at Qassim University, Saudi Arabia, found that there was deficiency of BLS knowledge among graduates and professionals which needs to be addressed; 8 their recommendations were to incorporate these life-saving skills as part of undergraduate curriculum with multiple reassessments to improve basic healthcare among the medical students. Similar observations were made regarding nurses and nursing students in a study comparing BLS knowledge between nurses of four hospitals and nursing students of ArabAmerican University in Jenin, Palestine. They recommended incorporation of BLS in curriculum of nursing students in their training years. ${ }^{9}$ Another research done in an indoor hospital resuscitation team in Turkey found that gender, seniority, time of the day or CPR duration did not affect the outcome of the BLS skills. ${ }^{10}$ This is similar to our study in terms of gender; however the authors have documented no effect on skill performances among different specialties, which differs from our research as it has yielded difference in performance based on seniority level of doctors. A research conducted in Africa found that clinical specialties fared better than non-clinical specialties in performing CPR. They concluded that general surgery and internal medicine trainees had a higher level of self-perceived confidence in emergency skills than their non-clinical counterparts. ${ }^{11}$ It was based on a questionnaire, however, and subjective perception in performing basic life support skills. In this study, the authors have practically tested doctors of various specialties, and found no significant difference in skills performance among clinical and non-clinical groups. Female medical students were found to be deficient in their knowledge in a study conducted in Saudi Arabia. However, this research was also based on subjective perceptions (questionnaire-based) and comparison with males was not included.12 These reasons are likely the cause of differing from our research where no significant difference was found in practical skills of BLS between males and females (Table I). To the authors' knowledge, this is the first study objectively analysing the difference in the skills performance of BLS between male and female doctors and among doctors of various specialties.

The importance of BLS courses for doctors all across the country cannot be emphasised enough since they not only encounter patients with sudden cardiac arrests within the hospital premises but outside it, as well. Unfortunately, this training is missing in most of medical fraternity; and this lack of theoretical knowledge and practical skills seriously impacts effective management of cardiac arrest both in- and out-of-the hospital. ${ }^{13} \mathrm{~A}$ research while analysing the performance of high school students of BLS techniques has recommended involvement of junior doctors in training programmes for high school students. ${ }^{14}$ Junior doctors would benefit from being involved in such programmes. Research conducted in the UK found that six-monthly refresher courses after initial training of basic life support for medical students, help retained their skills for a year. $15 \mathrm{lt}$ is imperative to start this training for medical students to let them cope with life-threatening emergencies of cardiac arrest, once they enter the practical world. Not only medical students but repeated BLS courses for all doctors, both rural and urban, specialists and nonspecialists, as well as nursing staff, would significantly help in reducing the mortality secondary to sudden cardiac arrests.

\section{CONCLUSION}

Gender, age and difference of specialties do not affect the skill performance of doctors undergoing BLS courses. Junior residents performance in practical skills of basic life support is borderline insignificant when compared to senior residents.

\section{CONFLICT OF INTEREST:}

Authors declared no conflict of interest.

\section{AUTHORS' CONTRIBUTION:}

SIZ, AS: Concept and designing of the proforma for the research, the result compilation and critical reviewing following data collection.

\section{REFERENCES}

1. Sayed ME, Assad RA, Aad YA, Gharios N, Refaat MM, Tamim H. Measuring the impact of emergency medical services (EMS) on out of hospital cardiac arrest in a developing country: A key metric for EMS systems' performance. Medicine (Baltimore) 2017; 96:e7570.

2. Weisfeldt ML, Sitlani CM, Ornato JP, Rea T, Aufderheide TP, Davis $\mathrm{D}$, et al. Survival after application of automated external defibrillators before arrival of the emergency medical services: Evaluation in the resuscitation outcomes consortium of population of 21 million. J Am Coll Cardiol 2010; 55:1713-20.

3. Ishtiaq O, Iqbal M, Zubair M, Qayyum R, Adil M. Outcome of cardiopulmonary resuscitation - predictors of survival. J Coll Physicians Surg Pak 2008; 18:3-7.

4. Morgan R, Westmoreland C. Survey of junior hospital doctors' attitudes to cardiopulmonary resuscitation. Postgrad Med $\mathrm{J}$ 2002; 78:413-5.

5. Ahmad A, Akhtar N, Mandal RK, Areeshi MY, Lohani M, Irshad M, et al. Knowledge of basic life support among the students of Jazan University, Saudi Arabia: Is it adequate to save a life? Alex J Med 2018; 54:555-9.

6. Khan H, Vora MK, Bose N. An education intervention to assess knowledge and practices about cardiopulmonary resuscitation (CPR) among nurses and nursing students of tertiary care hospital in Gujarat, West India. Eur J Pharm Med Res 2015; 2:502-11. 
7. Berg RA, Hemphill R, Abella BS, Aufderheide TP, Cave DM, Hazinski MF, et al. Part 5: Adult basic life support - 2010 American Heart Association guidelines for cardiopulmonary resuscitation and emergency cardiovascular care. Circulation 2010; 122:S685-705.

8. Almesned A, Almeman A, Alakhtar AM, AlAboudi AA, Alotaibi AZ, Al-Ghasham YA, et al. Basic life support knowledge of healthcare students and professionals in the Qassim University. Int $J$ health Sci 2014; 8:141-50.

9. Salameh B, Batran A, Ayed A, Zapen M, Ammash A, Taqatqa A, et al. Comparative assessment of basic life support knowledge between professional nurses and nursing students. Arch Med Health Sci 2018; 6:54-8.

10. Tok D, Keles GT, Tasyuz T, Yentür EA, Toprak V. Basic life support skills of doctors in a hospital resuscitation team. Tokohu J Exp Med 2004; 203:123-8.
11. Dufourg N, Goldstein LN, Botha M. Competence in performing emergency skills: How good do doctors think they really are? Afr J Emerg Med 2017; 7:151-6.

12. Al Mohaissen MA. Knowledge and attitudes towards basic life support among health students at a Saudi women's university. Sultan Qaboos Univ Med J 2017; 17:e59-e61.

13. Yunus M, Mishra A, Karim HMR, Raphael V, Ahmed G, Myrthong CE. Knowledge, attitude and practice of basic life support among junior doctors and students in a tertiary care medical institute. Int J Res Med Sci 2015; 3:3644-50.

14. Aaberg AMR, Larson CEB, Rasmussen BS, Hansen CM, Larsen JM. Basic life support knowledge, self-reported skills and fears in Danish high school students and effects of a 45-min training session run by junior doctors; a prospective cohort study. Scand J Trauma Resusc Emerg Med 2014; 22:24.

15. Lami M, Nair P, Gadhvi K. Improving basic life support skills for medical students. Adv Med Educ Pract 2016; 7:241-2.

........... 